Bahia - estadual

Postos de Serviço de Atendimento ao Cidadão

$206 / 96(\mathrm{~S})$

criação de postos de prestação de serviços públicos que reúnem em um mesmo espaço serviços como emissão de documentos, renovação de carteira de habilitaçäo etc.

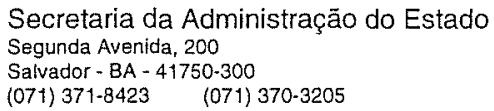

Vitória - ES - municipal

$165 / 96(S)$ Administração Estratégica

democratização da administração pública fundamentada em três métodos gerenciais: planejamento estratégico, orçamento popular e programa municipal de qualidade e produtividade.

Secretaria Municipal de Planejamento

Av. Marechal Mascarenhas de Moraes, 1.927

Vitória - ES - 29052-121

$\begin{array}{ll}\text { (027) } 335-8969 & \text { (027) } 335-8969\end{array}$

Nova Xavantina - MT - organização indígena 070/96 (F) Projeto Jaburu

gestão dos recursos naturais unindo conhecimentos tradicionais e científico na proteção da fauna e flora em busca de desenvolvimento auto-sustentado.

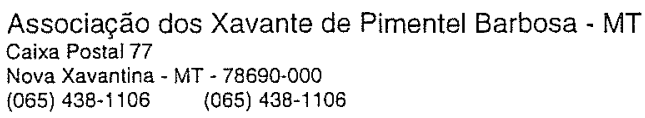

Minas Gerais - estadual

$186 / 96$

Integração com Municípios

articulação de esforços entre Estado e municípios para promover melhorias na escola pública, independentemente de vinculação às redes estadual ou municipal.

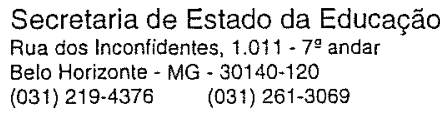

Minas Gerais - estadual

$240 / 96$

Programa de Desenvolvimento Empresarial

busca da excelência empresarial com a participação de todo - quadro de empregados, através de açōes voltadas à obtençāo dos resultados desejados pelos clientes.

Empresa de Assistência Técnica e Extensão Rural - MG Av. Raja Gabaglia, 1.626

Belo Horizonte - MG - 30050-540

$\begin{array}{lll}\text { (031) } 349-8090 & \text { (031) } 349-8095\end{array}$
Ceará - estadual

Modelo de Gestão Participativa

$181 / 96$

sistema de gestão envolvendo colegiados que funcionam como filtro entre as demandas sociais $e$ as divisōes do governo com o objetivo de aumentar a eficácia governamental.

Secretaria do Planejamento e Coordenação do Estado Centro Administrativo Governador Virgílio Távora

Fortaleza - CE - 60839-900

$\begin{array}{ll}\text { (085) } 274-1558 & \text { (085) } 274-1013\end{array}$

Vitória - ES - municipal

203/96

Melhoria das Condições de Atendimento do Abrigo

objetiva aprimorar o gerenciamento técnico e administrativo do abrigo para a populaçäo de rua, criando condiçōes para o resgate da cidadania.

Prefeitura Municipal de Vitória

Av. Marechal Mascarenhas de Moraes, 1.927

Vitória - ES - 29052-171

(027) $335-8777 \quad$ (027) $335-8966$

Campo Grande - MS - municipal

$202 / 96$ Programa de Qualidade e Produtividade

visa a melhoria da qualidade dos serviços prestados e do desempenho da administração pública, sendo gerenciado pelo Comitê Central de Qualidade.

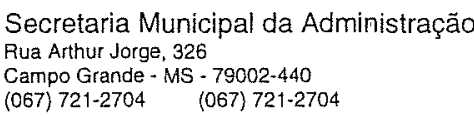

Minas Gerais - estadual

$239 / 96$ Processo de Planejamento na EMATER-MG

descentralização levando as decisōes de negócios para unidades mais próximas do cliente para que estas definam metas, negociando-as com seus superiores hierárquicos.

Empresa de Assistência Técnica e Extensão Rural - MG Av. Raja Gabaglia, 1.626

Belo Horizonte - MG - 30350-540

$\begin{array}{lll}\text { (031) } 349-8090 & \text { (031) } 349-8095\end{array}$

Belo Horizonte - MG - municipal

178/96 (D) Modelo de Gestão dos Resíduos Sólidos

minimizar os efeitos ambientais da geraçāo de resíduos e maximizar os benefícios, com tecnologia, participação da comunidade e qualificação dos servidores de limpeza urbana.

Superintendência de Limpeza Urbana - SLU/PBH

Rua Tupis, $149-12^{\circ}$ andar

Belo Horizonte - MG - 30190-060

(031) $277-6933 \quad$ (031) 201-8170 
Itabira - MG - municipal

$200 / 96$

Qualidade Total na Administração Pública Municipal

implementação de programa de qualidade total, atingindo todos os 1700 funcionários da prefeitura; elaboração do plano de açäo com a participação do funcionalismo.

Prefeitura Municipal de Itabira

Av. Carlos de Paula Andrade, 135 - Centro

Itabira - MG - 35900-206

$\begin{array}{ll}\text { (03i) } 831-7199 & \text { (031) } 831-7199\end{array}$

Juiz de Fora - MG - municipal

$241 / 96$

Programa Municipal de Alimentação Escolar

gerenciamento da merenda pelo município, possibilitando a utilização de alimentos frescos, reduzindo custos, melhorando qualidade e aumentando a disponibilidade.

Prefeitura Municipal de Juiz de Fora

Av. Fio Branco, 3.029

Juiz de Fora - MG - 36010-012

(032) 215-0962 ((032) 215-0972

Curitiba - PR - municipal

$166 / 96$

Rua da Cidadania do Carmo

criação de um ponto referencial com modernas e funcionais linhas arquitetônicas em local de fácil acesso com o objetivo de aproximar dos cidadãos a prestação de serviços públicos.

Secretaria do Governo Municipal

Av. Cândìio de Abreu, 817

Curitiba - PR - 80530-000

(041) $321-8130 \quad$ (041) $32 \uparrow-8522$

Teresina - PI - municipal

$184 / 96$

Censo de Vilas a Favelas de Teresina

recenseamento de vilas e favelas, com o envolvimento da comunidade na concepção e execução do trabalho, servindo de subsídio à definiçāo de políticas públicas.

Secretaria Municipal do Trabalho e de Assistência Social Praça Marechal Deodoro, 900

Teresina - PI - 64000-160

$\begin{array}{ll}\text { (086) } 221-5857 & \text { (086) } 221-7565\end{array}$

\section{Angra dos Reis - RJ - municipal \\ Programa de Prematrícula}

$187 / 96$

pré-matrícula nas escolas públicas municipais com o emprego de sistema informatizado, possibilitando priorização de acesso às vagas e atendimento planejado de demandas locais.

Secretaria Municipal de Educação

Praças Marquẽs de Tamandaré, 117

Angra dos Reis - RJ - 23900.000

(024) $365-0470 \quad(024) 365-0470$
Ituiutaba - MG - municipal

$009 / 96(\mathrm{~S})$

Programa de Ocupação Gerenciada

ocupação de áreas ociosas do patrimônio público municipal para o plantio de culturas temporárias destinadas à subsistência familiar.

\author{
Secretaria Municipal de Planejamento \\ Av $15, n^{2} 703$ \\ Ituiutaba - MG - 38300-000 \\ $\begin{array}{ll}\text { (034) } 261-2853 & \text { (034) } 261-6386\end{array}$
}

Morro da Garça - MG - municipal

$176 / 96$ Administração Pé no Chão

prefeito faz visitas regulares à zona rural do município com o objetivo de, junto com a populaçăo, traçar as prioridades da gestão.

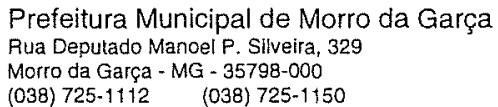

Curitiba - PR - municipal

$168 / 96$

Instituto de Pesquisa e Planejamento Urbano

órgão responsável pelo planejamento e principal agente da política de desenvolvimento de Curitiba, tendo se tornado referência para técnicos do país e do exterior.

Instituto de Pesquisa e Planejamento Urbano

Rua Bom Jesus, 669

Curitiba - PR - 80030-000

(041) $352-1414$

Rio de Janeiro - estadual

$182 / 96$

Pró-Baixada

estratégias regionais objetivando a articulação de projetos na Baixada Fluminense voltados ao estímulo do crescimento econômico e da oferta de serviços e infra-estrutura.

Secretaria de Estado para o Desenvolvimento da Baixada Fluminense e Municipios Adjacentes Rua Săo José, $35-15^{\circ}$ andar

Rio de Janeiro - RJ - 20010-020

(021) $533-7993 \quad$ (021) $533-5232$

Rio de Janeiro - RJ - municipal

$175 / 96$

Compras pelo Sistema de Registro de Preços

padronização de produtos e de seu controle de qualidade; simplificaçăo dos processos licitatórios; aumento da concorrência entre fornecedores.

Secretaria Municipal de Saúde

Rua Afonso Cavalcanti, 455 - Bloco 1 - sala 854

Rio de Janeiro - RJ - 20211- 110

(021) $293-4826 \quad$ (021) $503-2211$ 
Rio de Janeiro - RJ - municipal

$179 / 96$

Sistema de Codificação Institucional

mecanismo de acompanhamento e controle da evolução das estruturas organizacionais da administração municipal, permitindo a extração de relatórios e estatísticas gerenciais.

Subsecretaria de Desenvolvimento Institucional

Av. Afonso Cavalcanti, 455

Rio de Janeiro - RJ - 20211-110

$\begin{array}{ll}\text { (021) } 503-2797 & \text { (021) } 273-6641\end{array}$

Dois Lajeados - RS - municipal

201/96

Qualidade Total no Serviço Público

modelo administrativo alternativo que objetiva a melhoria da qualidade de atendimento à população, alicerçado na profissionalização dos funcionários e no avanço da informática.

Prefeitura Municipal de Dois Lajeados

Rua Doutor Afrânio $\mathrm{H}$. Lemos, 33

Dois Lajeados - RS - 90220-000

$\begin{array}{ll}\text { (054) } 471-1122 & \text { (054) } 471-1122\end{array}$

Porto Alegre - RS - municipal

Porto Alegre Mais - Cidade Constituinte

$177 / 96(F)$

fórum de debates que possibilita o envolvimento de todos os setores sociais no processo de planejamento urbano, propiciando a construção coletiva do futuro da cidade.

Secretaria de Planejamento Municipal

Av. Borges de Medeiros, 2.24

Porto Alegre - RS - $90110-150$

$\begin{array}{lll}\text { (051) } 221-0366 & \text { (051) } 221-0366\end{array}$

Rondônia - estadual

Novos Modelos de Gestão do Estado

$171 / 96(S)$

parcerias entre o governo estadual, governos municipais e organizações sociais comunitárias, delegando competências e ampliando ações no nível municipal.

Secretaria de Estado do Planejamento

Rua Padre Chiquinho, $s / n^{\circ}$

Porto Velho - RO - 78904-060

(069) 223-1246

Santa Catarina - estadual

$062 / 96$

Qualidade Total

programa de qualidade total, objetivando aumentar o moral dos servidores, melhorar a qualidade do atendimento e da prestação dos serviços, e diminuir custos operacionais.

Secretaria de Estado da Administração

Rua Tenente Silveira, $132-10^{\circ}$ andar

Florianópolis - SC - 88010-300

048) $223-1600$
Rio de Janeiro - RJ - municipal

$180 / 96$

Sistema de Dimensionamento da Força de Trabalho

sistema de coleta de dados para avaliação da força de trabalho do município com relação à capacidade ociosa, adequação a tarefas, distribuição e necessidades de treinamento.

Subsecretaria de Desenvolvimento Institucional Av. Afonso Cavalcanti, 455

Rio de Janeiro - RJ - 20211-110

(021) $293-3844 \quad$ (021) $273-6641$

Porto Alegre - RS - municipal

$023 / 96$ Orçamento Participativo

democratização da gestão dos recursos públicos através da participação de milhares de cidadãos na discussão $e$ decisões acerca das prioridades para os investimentos orçamentários.

Coordenadoria de Relações com a Comunidade

Praça Montevideo, 10

Porto Alegre - RS - 90010-170

$\begin{array}{lll}\text { (051) } 228-8597 & \text { (051) } 228-8725\end{array}$

Soledade - RS - municipal

Caravana Rural

$248 / 96$

interiorização da administração municipal, que se instala temporariamente em uma localidade da zona rural para executar serviços definidos pelas lideranças comunitárias.

Secr. Municipal de Agricultura, Pecuária e Meio Ambiente

Av. Júlio de Castilhos, 898

Soledade - RS - $99300-000$

$\begin{array}{lll}\text { (054) } 381-1699 & \text { (054) } 381-1933\end{array}$

Rondônia - estadual

$183 / 96(\mathrm{~S})$

Um Novo Modelo de Gestão

assistência técnica a pequenos produtores rurais em 41 municípios segundo os princípios básicos de planejamento participativo e descentralização de recursos e decisões.

Empresa de Assistência Técnica e Extensão Rural - RO Av. Farqhuar, 3.055

Porto Velho - RO - 78904-660

$\begin{array}{lll}\text { (069) } 223-2102 & \text { (069) } 223-3169\end{array}$

Santa Catarina - estadual

$185 / 96$

Programa de Qualidade Total

implantação do programa em todo o serviço público do Estado, envolvendo cerca de cem mil servidores e mais de cinco mil unidades de prestação de serviços.

Secretaria Extraordinária para Implantação do Programa de Qualidade e Produtividade no Serviço Público

Rua José da Costa Moellmann, 193

Florianópolis - SC - 88020-170

$\begin{array}{ll}\text { (048) } 221-3231 & \text { (048) } 221-3288\end{array}$ 
São Paulo - estadual

$169 / 96$

Reestruturação da Nossa Caixa-Nosso Banco

programa de recomposição da liquidez e de realinhamento operacional, baseado em vigorosa política de contenção de despesas e de alteração da estrutura organizacional.

Nossa Caixa-Nosso Banco S/A

Rua XV de Novembro, 111 - $11^{\circ}$ andar

Säo Paulo - SP - 01013-001

$\begin{array}{ll}\text { (011) } 244-6008 & \text { (011) } 604-5094\end{array}$

São Paulo - estadual

$242 / 96$

Sistema UNESP de Treinam. p/ Elaboração de Projetos

objetiva desenvolver capacidades necessárias ao planejamento participativo e descentralizado, criando condiçōes para a melhoria dos processos e maior eficiência dos serviços.

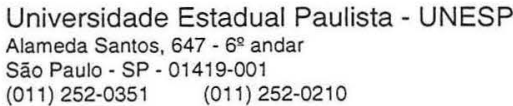

Campinas - SP - municipal $173 / 96$

Novo Modelo de Gestão da Prefeitura de Campinas

ação intersecretarial na criação de quatro órgãos regionalizados responsáveis por todos os serviços públicos; reestruturação administrativa orientada para programas e projetos.

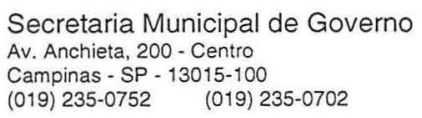

Santos - SP - municipal

$174 / 96(S)$

Ouvidoria Pública Municipal

recebe reclamações sobre a prestação de serviços e as encaminha ao órgão responsável; suas advertências e recomendações constituem a voz da opinião pública.

Prefeitura Municipal de Santos

Praça Mauá, $s / n^{\circ}$

Santos - SP - 11010-000

(013) 219-7000
São Paulo - estadual

$172 / 96$

Programa de Gerenciamento Costeiro

gestão integrada e participativa dos recursos naturais da zona costeira do Estado, buscando adequar as atividades humanas ao suporte ambiental.

Secretaria do Meio Ambiente

Av. Professor Frederico Hermann Jr., 345

São Paulo - SP - 05459-010

$\begin{array}{ll}\text { (011) } 210-5478 \quad \text { (011) } 210-6100 & 0\end{array}$

Campina do Monte Alegre - SP - municipal $\quad 167 / 96$ Democracia Caipira

modelo de gestão pública sem funcionários no qual os recursos públicos são geridos com a participação de conselhos populares, e $100 \%$ dos serviços públicos são terceirizados.

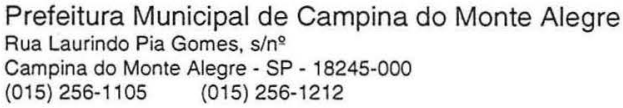

Diadema - SP - municipal

Municipalização e Participação Popular

$170 / 96(S)$

busca o estabelecimento de políticas e a melhoria dos serviços públicos de saneamento através da participação popular em reuniões plenárias.

Companhia de Saneamento de Diadema - SANED

Rua Estados Unidos, 78

Diadema - SP - $09921-030$

(011) $745-9305 \quad$ (011) $745-9326$

São José dos Campos - SP - municipal

$247 / 96$ Programa Bairro Vivo

objetiva levar aos bairros uma "força-tarefa", com ações que integram todas as secretarias municipais, potencializando os canais de participação popular.

Prefeitura Municipal de São José dos Campos

Rua José de Alencar, 123

São José dos Campos - SP - 12209-530

(012) $341-5277$ $\begin{array}{lc}\text { Franca - SP - municipal } & 197 / 96 \\ \text { Projeto GATHU - Grupo de Apoio aos Talentos Humanos }\end{array}$

projeto de desenvolvimento da política de recursos humanos da prefeitura com a participação de servidores voluntários, que se reúnem periodicamente para discutir e propor.

Secretaria Municipal de Administração

Rua Frederico Moura, 1.517

Franca - SP - 14401-150

$\begin{array}{lll}\text { (016) } 723-9000 & \text { (016) } 723-5291\end{array}$
Jundiaí - SP - municipal

Seminários Internos

$204 / 96$

programa de participação e integração de todos os órgãos municipais, a partir de grupos temáticos, na busca de soluções administrativas e organizacionais.

Coordenadoria Municipal de Planejamento

Av, da Liberdade, $s / n^{2}$ - Hortolândia

Jundiai - SP - 13214-015

$\begin{array}{lll}\text { (011) } 7392-8877 & \text { (011) } 7392-5405\end{array}$ 
Santa Cruz do Rio Pardo - SP - municipal $\quad 245 / 96$

Patrimônio Público \& Memória da Comunidade

objetiva sensibilizar a comunidade para a preservação do primeiro grupo escolar construído no município em 1913, que hoje é sede da Delegacia de Ensino.

Delegacia de Ensino Professor Gentil Marques Válio

Usina Velha - Caixa Postal no 152

Santa Cruz do Rio Pardo - SP - 18900-000

$\begin{array}{ll}\text { (014) } 372-1777 & \text { (014) } 372-1520\end{array}$

Paraná - estadual

$046 / 96$

Fundação Escola de Administração Pública Municipal

atuação junto a prefeituras e câmaras municipais com o objetivo de orientar os agentes públicos sobre as melhores formas de emprego do dinheiro público.

Tribunal de Contas do Estado do Paraná

Rua Alcides T. de Carvalho, 300

Curitiba - PR - 81520-230

(041) $276-4966$
Campo Mourão - PR - municipal

Orçamento Participativo

democratização das decisões sobre o uso dos recursos públicos através da participação popular na escolha das obras prioritárias para cada localidade.

Secretaria do Planejamento

Rua Brasil, 835 - Centro

Campo Mourăo - PR - 87301-140

$\begin{array}{ll}\text { (044) } 822-1144 & \text { (044) } 822-1554\end{array}$

Angra dos Reis - RJ - municipal

$199 / 96(S)$

Sistema de Acompanhamento Orçamentário

novos procedimentos de acompanhamento e detalhamento das despesas municipais, resultando no incremento da gestão e na democratização das informações.

Secretaria Municipal de Planejamento

Rua da Conceição, 213

Angra do Reis - RJ - 23900-000

$\begin{array}{ll}\text { (024) } 365-4360 & \text { (024) } 365-1255\end{array}$

\begin{abstract}
Vitória - ES - municipal
Revista Finanças dos Municípios Capixabas

$620 / 96$

publicação de alcance estadual que objetiva fornecer instrumentos de análise das finanças municipais, subsidiando diagnóstico da realidade sobre a qual se deseja intervir.
\end{abstract}

Secretaria Municipal de Fazenda de Vitória Av. Mascarenhas de Moraes, $1.927-2^{2}$ andar

Vitória - ES - 29010-331

$\begin{array}{lll}(027) 335-8593 & \text { (027) } 335-8970\end{array}$
Governador Valadares - MG - municipal

$188 / 96(S)$ Justiça Tributária

ingressos para jogos de futebol são trocados com os contribuintes que apresentem notas fiscais de empresas da cidade, propiciando aumento na arrecadação.

Prefeitura Municipal de Governador Valadares

Rua Marechal Floriano, 805

Governador Valadares - MG - 35010-140

$\begin{array}{lll}\text { (033) } 271-2256 & \text { (033) } 271-1566\end{array}$ 
Nova Santa Bárbara - PR - municipal

$249 / 96$ Imposto Único Municipal

reunião de vários tributos (IPTU, ISS, contribuição de melhoria, taxa de iluminação) em um único imposto, racionalizando o sistema e facilitando a vida do contribuinte.

Prefeitura Municipal de Nova Santa Bárbara

Rua Waltredo Bittencourt de Moraes, 222

Nova Santa Bärbara - PR - 86250-000

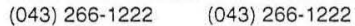

São Paulo - estadual

205/96

Análise e Acompanhamento das Finanças Municipais

desenvolvimento de estudos, publicações e relatórios gerenciais, distribuídos gratuitamente aos municípios, com 0 objetivo de difundir informações sobre finanças públicas.

Fundação Prefeito Faria Lima - CEPAM

Av. Prot. Lineu Prestes, 913 - Cidade Universitária

São Paulo - SP - 05508-900

$\begin{array}{ll}\text { (011) } 816-6460 & \text { (011) } 813-5969\end{array}$
São Paulo - estadual

$190 / 96$

Programa de Informatização Municipal - PIM

programa de capacitação de recursos humanos e de planejamento para a informatização das áreas legislativa e fiscal dos municípios de pequeno e médio porte.

Fundação Prefeito Faria Lima - CEPAM

Av. Prof. Lineu Prestes, 913 - Cidade Universitária

São Paulo - SP - 05508-900

$\begin{array}{lll}\text { (011) } 816-6460 & \text { (011) } 813-5969\end{array}$

Bauru - SP - municipal

$189 / 96(\mathrm{~S})$

Cartão do Contribuinte Municipal - CCM

de posse de um cartão magnético, o contribuinte tem à disposição, via terminais em diversos pontos da cidade, informações "on line" sobre sua situação tributária.

Prefeitura Municipal de Bauru

Rua Benjamin Constant, 6-46

Bauru - SP - 17013-540

(014) $234-2520 \quad$ (014) $223-3319$
Vitória - ES - municipal $\quad 211 / 96$

Reestruturação do Sistema de Arquivamento

política de gestão de documentos com o objetivo de tornar mais eficiente o processo de obtenção de informações junto ao Arquivo do Município.

Secretaria Municipal de Administração

Rua Comissário Otávio de Queiroz, 45

Vitória - ES - 29060-270

(027) 225-6937

Belo Horizonte - MG - municipal

$250 / 96(S)$

Programa de Democratização de Informações

reorganização, integração e descentralização dos serviços de informação ao público, utilizando tecnologias atuais, com vistas à integração política e administrativa.

Secretaria Municipal de Governo

Av. Afonso Pena, 1.212 - sala 224

Belo Horizonte - MG - 31130-003

$\begin{array}{lll}\text { (031) } 277-4319 & \text { (031) } 277-4275\end{array}$

Londrina - PR - municipal

Núcleo de Informação em Mortalidade

$196 / 96(S)$

refinamento dos dados sobre mortalidade, possibilitando um melhor conhecimento das mortes por causas indefinidas e, conseqüentemente, maior eficácia no seu combate.

Autarquia do Serviço Municipal de Saúde

Av. Duque de Caxias, 635

Londrina - PR - 86015-000

$\begin{array}{lll}\text { (043) } 330-2500 & \text { (043) } 321-3544\end{array}$
Minas Gerais - estadual

208/96 Retrato de Minas

desenvolvimento de software para a montagem de uma base de estatísticas sobre os municipios mineiros, propiciando maior agilidade no processo de acesso às informações.

Fundação João Pinheiro

Alameda das Acácias, $70-5^{\circ}$ andar

Belo Horizonte - MG - 31215-150

$\begin{array}{lll}\text { (031) } 448-9701 & \text { (031) } 448-9699\end{array}$

Betim - MG - municipal

Sistema de Informações Municipais

Geoprocessamento

objetiva subsidiar o planejamento da cidade, sendo operacionalizado por servidores municipais especialmente treinados para esta finalidade.

Secretaria de Planejamento e Operacionalização

Rua Professor Osvaldo Franco, 55

Betim - MG - 32510-000

$\begin{array}{ll}\text { (031) } 539-2223 & \text { (031) } 531-2643\end{array}$

São Mateus do Sul - PR - municipal

$194 / 96$

Administração Financeira e Cidadania

planejamento e controle dos recursos financeiros, resultando em equilibrio orçamentário e propiciando investimentos em diversas áreas.

Prefeitura Municipal de São Mateus do Sul

Rua Barão do Rio Branco, 431 - Caixa Postal no 14

Săo Mateus do Sul - PR - 83900-000

$\begin{array}{ll}\text { (042) } 532-1122 & \text { (042) } 532-1746\end{array}$ 
Angra dos Reis - RJ - municipal

$210 / 96$

Automação da Rede Municipal

implantação de um sistema de gerenciamento e produção de informações capaz de controlar as rotinas administrativas e pedagógicas do órgão.

Secretaria Municipal de Educação

Praça Marquês de Tamandaré, 116

Angra dos Reis - RJ - 23900-000

$\begin{array}{ll}\text { (024) } 365-0470 & \text { (024) } 365-0470\end{array}$

Rio Grande do Sul - estadual $192 / 96$

Sistema de Informações Geográficas Pró-Guaíba

base de dados de apoio ao planejamento e ao gerenciamento ambiental que permite um monitoramento do meio físico, com menores custos operacionais e em menor tempo.

Companhia Riograndense de Saneamento

Rua Caldas Júnior, $120-17^{2}$ andar

Porto Alegre - RS - 90010-260

$\begin{array}{lll}(051) & 228-5622 & \text { (051) } 228-2694\end{array}$

São Paulo - estadual $212 / 96$

Organização do Sistema Municipal de Informação

permite aos municípios sistematizar informações sobre unidades imobiliárias, equipamentos e serviços, indicadores sociais etc., subsidiando controle e planejamento.

Fundação Prefeito Faria Lima - CEPAM

Av. Prof. Lineu Prestes, 913 - Cidade Universitária

São Paulo - SP - 05508-900

$\begin{array}{ll}\text { (011) } 816-6460 & \text { (011) } 813-5969\end{array}$

São José dos Campos - SP - municipal

$195 / 96(\mathbf{S})$ Serviço 156

serviço telefônico de informações sobre transporte público, concursos, tributos, campanhas de vacinaçāo etc., além de atendimento de solicitações diversas.

Secretaria de Governo do Município

Rua José de Alencar, 123

São José dos Campos - SP - 12209-530

$\begin{array}{lll}\text { (012) } 340-8156 & \text { (012) } 340-8010\end{array}$
Rio de Janeiro - RJ - municipal

$191 / 96$

Indicadores de Performance Organizacional

instrumento de análise de desempenho dos órgãos da prefeitura e de apoio a decisões sobre a modelagem de estruturas organizacionais.

Subsecretaria de Desenvolvimento Institucional

Rua Afonso Cavalcanti, 455

Rio de Janeiro - RJ - 20211-110

$\begin{array}{lll}\text { (021) } 273-6641 & \text { (021) } 503-2797\end{array}$

São Paulo - estadual

209/96

\section{Sistema CEPAM de Videotexto}

sistema que possibilita a comunicação direta dos municípios entre si e com o CEPAM, permitindo consultas técnicas e o acesso a bases de dados.

Fundação Prefeito Faria Lima - CEPAM

Av. Prot. Lineu Prestes, 913 - Cidade Universitária

São Paulo - SP - 05508-900

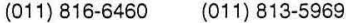

São Paulo - estadual

$213 / 96$

Rede Comunicação de Experiências Municipais RECEM

captação sistemática e uso das informações referenciais sobre experiências municipais que buscam alternativas de soluções para os diversos setores da administração municipal.

Fundação Prefeito Faria Lima - CEPAM

Av. Prof. Lineu Prestes, 913 - Cidade Universitária

São Paulo - SP - 05508-900

(011) $816-6460 \quad$ (011) $813-5969$

São José dos Campos - SP - municipal

$207 / 96$ Guia Eletrônico de Serviços Públicos

disponibilização, através do telefone 156, de informações sobre como e onde obter o serviço público desejado, com a indicação inclusive dos documentos necessários.

Departamento de Informática

Rua José de Alencar, $123-2^{2}$ subsolo

São José dos Campos, - SP - 12209-530

$\begin{array}{lll}\text { (012) } 340-8191 & \text { (012) } 340-8010\end{array}$

\section{Consórcios Intermunicipais}

São Paulo - estadual

$215 / 96$

Formas de Cooperação Intermunicipal

São Paulo - estadual

$216 / 96$

Formação de Consórcios Intermunicipais de Informática

pesquisa que objetiva organizar informações sobre experiências de cooperação intermunicipal, subsidiando prefeituras que tenham interesse em se associarem.

Fundação Prefeito Faria Lima - CEPAM

Av. Prof. Lineu Prestes, 913 - Cidade Universitária

São Paulo - SP - 05508-900

$\begin{array}{ll}\text { (011) } 816-6460 & \text { (011) } 813-5969\end{array}$ objetivam prover serviços de processamento eletrônico de dados às prefeituras integrantes, viabilizando organizacional e economicamente a modernização tecnológica.

Fundação Prefeito Faria Lima - CEPAM

Av. Prof. Lineu Prestes, 913 - Cidade Universitária

São Paulo - SP - 05508-900

$\begin{array}{ll}\text { (011) } 816-6460 & \text { (011) } 813-5969\end{array}$ 


\author{
Franca - SP - intermunicipal \\ $214 / 96$ \\ COMAM - Consórcio de Municípios da Alta Mogiana
}

reúne dezessete cidades da região de Franca e objetiva a descentralização das gestões governamentais, a integração e a cooperação regional.

Secretaria de Governo de Franca

Rua Frederico Moura, 1.517

Franca - SP - 14401-150

$\begin{array}{lll}\text { (016) } 723-5291 & \text { (016) } 723-9900\end{array}$

\title{
ADMINISTRACÃ̃O E GOVERNO
}

Participação Popular

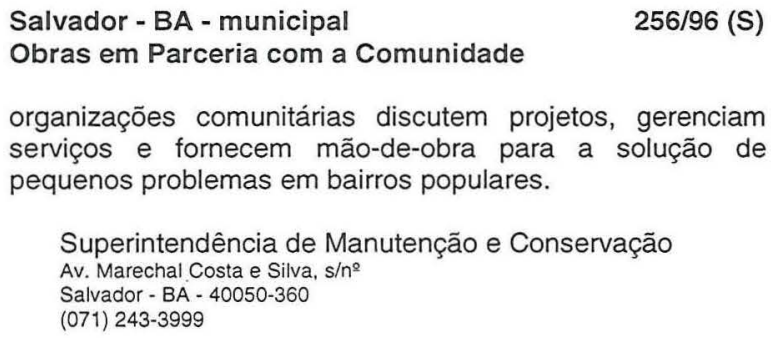

organizaçōes comunitárias discutem projetos, gerenciam serviços e fornecem mão-de-obra para a solução de pequenos problemas em bairros populares.

$256 / 96(S)$

Quixadá - CE - municipal

$243 / 96$

Programa Prefeitura com Você

visa estimular e garantir a participação popular em reuniões e plenárias nos bairros, fortalecendo as associações e conselhos populares.

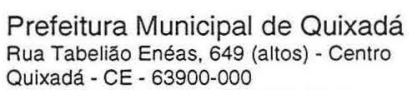

Cuiabá - MT - municipal

$231 / 96(S)$

Gerenciamento Comunitário

utilização de fiscais comunitários no trabalho de fiscalização referente às posturas municipais, à vigilância sanitária, e ao parcelamento, uso e ocupação do solo urbano.

Secretaria do Meio Ambiente e Desenvolvimento Urbano Praça Alencastro, $\operatorname{s/n} \mathrm{n}^{2}$ - Palácio Alencastro - $5^{2}$ andar Cuiabá - MT - 78005-580

$\begin{array}{lll}\text { (065) } 322-8970 & \text { (065) } 322-8970\end{array}$

Belo Horizonte - MG - municipal

$217 / 96$

Cidadania, Educação e Afetividade na Construção da Participação Popular

participação ativa da população na elaboração do orçamento de limpeza urbana e na discussão da ação dos catadores de papel; parcerias diversas com a sociedade organizada.

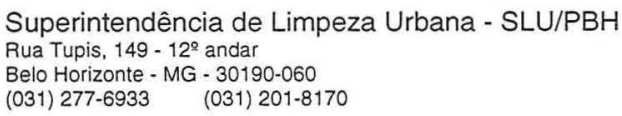

Ceará - estadual 227/96

Combate à Pobreza Rural no Ceará - Projeto São José

geração de emprego e renda através do financiamento de projetos nas áreas produtiva, social e de infra-estrutura, a partir de propostas de associações comunitárias.

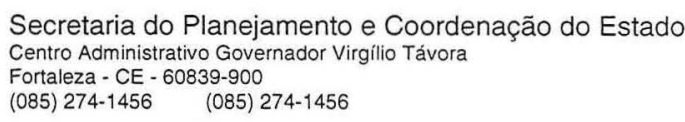

Vitória - ES - municipal

$229 / 96$

Orçamento Popular

tem como princípios o conhecimento e visão global da cidade, resgate da cidadania, democratização das decisões e execução das obras priorizadas pela população.

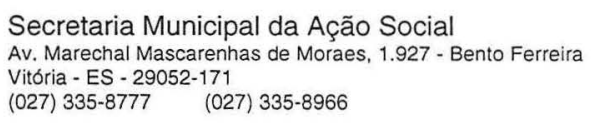

Minas Gerais - estadual

$255 / 96$

Audiências Públicas Regionais

realização de audiências públicas com o objetivo de subsidiar com informações o trabalho parlamentar, o planejamento estadual e a elaboração da proposta orçamentária.

Assembléia Legislativa do Estado

Rua Rodrigues Caldas, 79 - $18^{\circ}$ andar - Santo Agostinho

Belo Horizonte - MG - 30190-120

$\begin{array}{lll}\text { (031) } 290-7686 & \text { (031) } 290-7613\end{array}$

Belo Horizonte - MG - municipal

$221 / 96$

Conselho Municipal de Transporte e Trânsito

canal permanente e democrático para a população discutir e elaborar propostas, controlar serviços de transporte e trânsito e exigir 0 atendimento das reivindicações dos usuários.

Empresa de Transportes e Trânsito de Belo Horizonte Av. Engenheiro Carlos Goulart, s $/ \mathrm{n}^{\circ}$ - Bairro Buritis Belo Horizonte - MG - 30455-700

$\begin{array}{ll}\text { (031) } 277-7521 & \text { (031) } 277-7575\end{array}$ 
Belo Horizonte - MG - municipal

$252 / 96$

Orçamento Participativo

realização de três assembléias em cada uma das nove regiões com discussão e seleção de prioridades e escolha dos delegados que compõem as instâncias superiores.

Prefeitura Municipal de Belo Horizonte

Av. Afonso Pena, 1.212

Belo Horizonte - MG - 30130-003

$\begin{array}{ll}\text { (031) } 277-4445 & \text { (031) } 277-4074\end{array}$

Ipatinga - MG - municipal

$232 / 96$

Participação Popular na Saúde

através de comissões locais o Conselho Municipal de Saúde controla e define a política de saúde, incorporando a participação popular ao planejamento e gerência das unidades.

Prefeitura Municipal de Ipatinga

Av. Concórdia, $s / n^{\circ}$ - Centro

Ipatinga - MG - 35160-011

$\begin{array}{ll}\text { (031) } 829-8555 & \text { (031) } 829-8557\end{array}$

Paraná - estadual

$226 / 96(S)$

SISDADANIA - Sistema Integrado da Cidadania

através de módulos sistêmicos (programas) o projeto permite a recepção de reivindicações da população e a participação de grupos de servidores na busca de soluções administrativas.

Ouvidoria Geral do Estado

Rua Marechal Hermes, 751 - $4^{\circ}$ andar

Curitiba - PR - 80530-230

$\begin{array}{ll}\text { (041) } 252-7119 & \text { (041) } 253-7451\end{array}$

Curitiba - PR - municipal

$257 / 96$

Bairro Total

programa de encontro com a comunidade dos bairros de Curitiba, em assembléias públicas, nas quais se discutem necessidades e demandas de cada região.

Secretaria do Governo Municipal

Av. Cândido de Abreu, 817

Curitiba - PR - 80530-000

$\begin{array}{lll}\text { (041) } 321-8130 & \text { (041) } 321-8522\end{array}$

Nova Santa Bárbara - PR - municipal

$230 / 96$

Disque-Balancete

sistema de controle financeiro-contábil através do qual todo cidadão pode solicitar cópias do balancete e outras informações específicas sobre a receita e a despesa.

Prefeitura Municipal de Nova Santa Bárbara

Rua Walfredo Bittencourt de Moraes, 222

Nova Santa Bárbara - PR - 86250-000

$\begin{array}{ll}\text { (043) } 266-1222 & (043) 266-1222\end{array}$
Ipatinga - MG - municipal

Orçamento Participativo

$061 / 96(S)$

ampliação do poder popular de influenciar as decisões sobre gastos públicos na medida em que as prioridades são inicialmente escolhidas em assembléias regionais.

Secretaria do Planejamento de Ipatinga

Praça Três Poderes, $s / n^{\circ}$

Ipatinga - MG - 35160-000

$\begin{array}{ll}\text { (031) } 829-8600 & \text { (031) } 829-8610\end{array}$

Itabira - MG - municipal

$218 / 96$

Governo Itinerante - Vendo o Futuro Acontecer

lideranças comunitárias juntamente com o prefeito e secretários definiram quatro prioridades para cada uma das seis regiōes urbanas e três regiōes rurais em que foi dividida a cidade.

Prefeitura Municipal de Itabira

Av. Carlos de Paula Andrade, 135 - Centro

Itabira - MG - 35900-206

$\begin{array}{ll}\text { (031) } 831-6600 & \text { (031) } 831-6600\end{array}$

Candói - PR - municipal

$024 / 96$

Participação Popular

identificação dos anseios da comunidade e estabelecimento de metas a partir da realização de reuniões regionais de um dia de duração abertas à participação popular.

Prefeitura Municipal de Candói

Av. XV de Novembro, 900

Candói - PR - 85130-000

$\begin{array}{ll}\text { (042) } 738-1114 & \text { (042) } 738-1114\end{array}$

Londrina - PR - municipal

$228 / 96$

Orcamento Participativo

em reuniōes regionais, a população aponta as obras prioritárias para seus bairros e elege representantes para o Conselho do Orçamento Participativo.

Prefeitura Municipal de Londrina

Av. Duque de Caxias, 635

Londrina - PR - 86015-000

$\begin{array}{ll}\text { (043) } 330-3001 & \text { (043) } 336-1274\end{array}$

Recife - PE - municipal

$026 / 96$

Programa Prefeitura nos Bairros

participação popular na gestão da cidade e na montagem do orçamento público; anualmente é realizado seminário de avaliação de metodologia do trabalho para ajustes no processo.

Secretaria de Políticas Sociais

Cais do Apolo, $925-6^{\circ}$ andar

Recife - PE - 50030-230

$\begin{array}{lll}\text { (081) } 224-7853 & \text { (081) } 424-1862\end{array}$ 


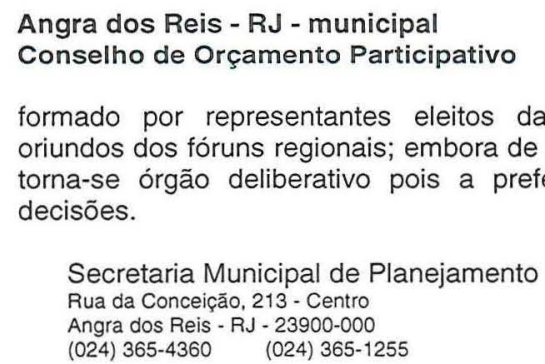
decisões.

Secretaria Municipal de Planejamento

Rua da Conceiçăo, 213 - Centro

Angra dos Reis - RJ - 23900-000

$\begin{array}{ll}\text { (024) } 365-4360 & \text { (024) } 365-1255\end{array}$

$223 / 96(S)$

formado por representantes eleitos da sociedade civil, oriundos dos fóruns regionais; embora de caráter consultivo, torna-se órgão deliberativo pois a prefeitura acata suas

Angra dos Reis - RJ - municipal

254/96

Democratização da Gestão na Rede Municipal de Ensino

diretores e membros dos conselhos de escola passaram a ser eleitos, consolidando os pólos de discussão sobre a gestão como espaços de participação popular.

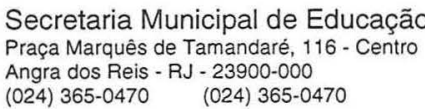

Soledade - RS - municipal

$258 / 96$

Mutirão Urbano

realização de reuniōes com lideranças de bairro para levantamento de necessidades, ocasiões em que ocorre também a prestação de serviços de saúde e outros.

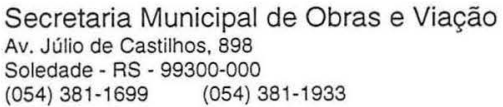

São Paulo - estadual

$225 / 96$

Projeto Conselho de Saúde

objetiva viabilizar a participação real da população para a construção do SUS através de técnicas pedagógicas e ludopedagógicas.

Centro de Vigil. Epidemiológica Prof. Alexandre Vranjac Av. São Luis, $99-7^{\circ}$ andar - Centro

São Paulo - SP - 01046-001

(011) $258-6416 \quad$ (011) $257-7611$

Diadema - SP - municipal

$253 / 96$

Participação Popular em Saúde

- Conselho Popular de Saúde, composto por sessenta moradores da cidade, debate e aprova planos e programas para a área, em um processo de intensa participação popular.

Secretaria Municipal de Saúde

Rua Felipe Camarāo, 287 - Centro

Diadema - SP - 09911-340

$\begin{array}{lll}\text { (011) } 450-5815 & \text { (011) } 445-7407\end{array}$

\section{Angra dos Reis - RJ - municipal \\ $224 / 96$}

Gestão Democrática e Apropriação do Solo

criação do Conselho Municipal de Urbanismo e Meio Ambiente, composto por quinze membros da sociedade civil e seis do poder público com o objetivo de democratizar a política urbana.

Secretaria Municipal de Planejamento

Rua da Conceiçăo, 213 - Centro

Angra dos Reis - RJ - 23900-000

$\begin{array}{lll}\text { (024) } 365-4360 & \text { (024) } 365-1255\end{array}$

Soledade - RS - municipal

$238 / 96$

Orçamento Participativo

dois representantes comunitários de cada bairro formam o Conselho de Representantes, que aponta as obras a serem prioritariamente incluídas no orçamento.

Prefeitura Municipal de Soledade

Av. Júlio de Castilhos, 898

Soledade - RS - $99300-000$

$\begin{array}{ll}\text { (054) } 381-1699 & \text { (054) } 381-1933\end{array}$

São Paulo - estadual

$220 / 96$

Exercício Direto do Poder pelo Povo

publicação de manual sobre participação popular e o papel dos governos municipais, oferecendo orientação sobre mecanismos constitucionais de exercício da cidadania.

Fundação Prefeito Faria Lima - CEPAM

Rua Donato Luongo, 58 - Água Fria

Săo Paulo - SP - 02409-030

(011) 203-9572

Pedreira - SP - estadual

$219 / 96$

Locação do Muro Escolar

a locação do muro da escola propiciou a remodelação do prédio, que está hoje bem equipado e conservado, tudo resultando em bons indices de aproveitamento escolar.

E.E.P.G. Professor Arnaldo Rossi

Rua Paroma, 404 - Jaguariuna

Pedreira - SP - 13920-000

(019) $867-1837$

Franca - SP - municipal

Orçamento Participativo

$222 / 96$

a partir de reuniōes nos bairros, que apontam necessidades e escolhem delegados, é desencadeado o processo de consulta popular sobre o orçamento.

Secretaria de Governo de Franca

Rua Frederico Moura, 1.517

Franca - SP - 14401-150

$\begin{array}{ll}\text { (016) } 723-5291 & \text { (016) } 723-9900\end{array}$ 


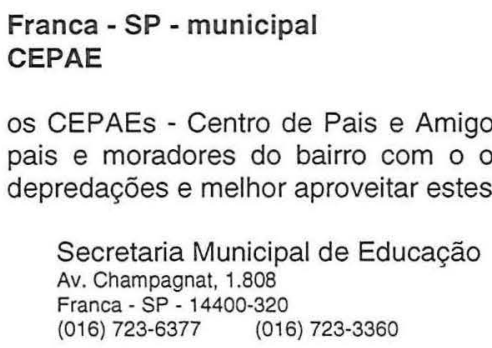

interferência na realidade dos trabalhadores de carvoarias e destilarias com desdobramentos em várias frentes de ação buscando a melhoria das condições de trabalho.

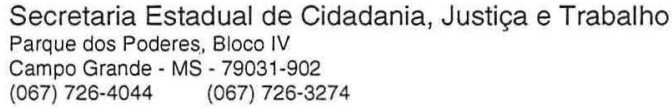

Belo Horizonte - MG - municipal

236/96

Valoriz. e Qualificação do Trabalhador na Limpeza Urbana

capacitação e reciclagem do corpo técnico e administrativo, visando valorização e maior dinamismo organizacional através de cursos, estímulo a publicações etc.

Superintendência de Limpeza Urbana - SLU/PBH

Rua Tupis, $149-12^{2}$ andar

Belo Horizonte - MG - 30190-060

$\begin{array}{ll}\text { (031) } 277-6933 & \text { (031) } 201-8170\end{array}$

Itabira - MG - municipal $478 / 96$

Valorização e Incentivo à Vida dos Alcoolistas

busca a recuperação e reintegração do servidor dependente através de campanha motivacional, palestras, entrevistas, discussões em grupo etc.

Prefeitura Municipal de Itabira

Av. Carlos de Paula Andrade, 135

Itabira - MG - 35900-206

$\begin{array}{lll}\text { (031) } 831-6600 & \text { (031) } 831-6600\end{array}$

Redenção - PA - municipal $035 / 96$

\section{Gestão da Qualidade Total no Serviço Público}

com o objetivo de melhorar o atendimento, o programa atua na mudança da consciência e da cultura administrativa dos servidores.

Prefeitura Municipal de Rendenção

Av. Santa Teresa, 214

Rendenção - PA - 68552-230

$\begin{array}{lll}\text { (091) } 424-1850 & \text { (091) } 424-1984\end{array}$

programa de valorização e incentivos dos servidores do Sistema Único de Saúde de Belo Horizonte através de complementação salarial, criação de função gratificada etc.

Secretaria Municipal de Saúde

Av. Afonso Pena, 2.336 - 3ํandar

Belo Horizonte - MG - 30130-007

$\begin{array}{ll}\text { (031) } 277-7806 & \text { (031) } 277-2807\end{array}$

Betim - MG - municipal

$237 / 96$

Projeto Rever

programa de qualificação e formação de servidores em busca de seu envolvimento na remodelação e aprimoramento da administração pública.

Secretaria Municipal de Administração

Rua Professor Osvaldo Franco, 55

Betim - MG - 32510-000

$\begin{array}{ll}\text { (031) } 539-2131 & \text { (031) } 531-2643\end{array}$

Itabira - MG - municipal

$479 / 96$

Gerência do Desempenho

avaliação de desempenho profissional que subsidia a capacitação de servidores e plano de cargos e carreiras, aprimorando a prestação dos serviços.

Prefeitura Municipal de Itabira

Av. Carlos de Paula Andrade, 135

Itabira - MG - 35900-206

$\begin{array}{lll}\text { (031) } 831-6600 & \text { (031) } 831-6600\end{array}$

Bom Princípio - RS - municipal

Construção do Caminho da Serra Shopping

$244 / 96$

incentivo ao desenvolvimento da cultura de morango, evitando o êxodo rural, aumentando o potencial turístico e, conseqüentemente, a arrecadação de tributos.

Prefeitura Municipal de Bom Princípio

Av. Guilherme Winter, 65

Bom Principio - RS - $95765-000$

$\begin{array}{lll}\text { (051) } 634-1342 & \text { (051) } 534-1122\end{array}$ 
$235 / 96$

Capacitação do Funcionário Público do Estado

sistematização das ações de capacitação do funcionário público a partir de ações coordenadas envolvendo vinte e oito instituições públicas.

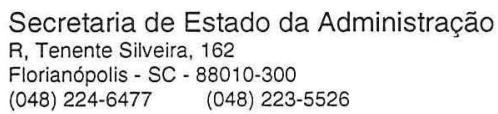

Araraquara - SP - estadual

$246 / 96(S)$

Curso de Administração Municipal

através de parcerias com o CEPAM e prefeituras da região foi estruturado o curso de administração municipal, voltado à profissionalização e formação de gestores públicos.

Faculdade de Ciências e Letras de Araraquara - UNESP Rodovia Araraquara-Jaú, km 1 - Caixa Postal no 174

Araraquara - SP - 14800-901

$\begin{array}{ll}\text { (016) } 232-1362 \quad \text { (016) } 232-0444 & 0\end{array}$
Florianópolis - SC - municipal

Avaliação de Desempenho no Serviço Público

$055 / 96$

objetiva a melhoria na qualificação de servidores em estágio probatório, identificando as necessidades de capacitação, readaptação e remanejamento.

Centro de Desenv. de Recursos Humanos em Saúde

Rua Esteves de Júnior, 160 - Centro

Florianópolis - SC - 88015-530

$\begin{array}{lll}\text { (048) } 221-2210 & \text { (048) } 221-2029\end{array}$

Santo André - SP - municipal

036/96

Programa de Dependência Química

objetiva a prevenção e recuperação do funcionário dependente quimico (álcool e drogas) através de apoio grupal, palestras e outras iniciativas.

Serviço Municipal de Água e Saneamento de Santo André

Rua Joảo Meneguel, 152 - Rudge Ramos

São Bernardo do Campo - SP - 09730-570

$\begin{array}{ll}\text { (011) } 411-9681 & \text { (011) } 411-9677\end{array}$ 